\title{
Cuanto más simple, mejor: análisis de las prácticas sobre la constitución y las formas de administración de las sociedades por acciones en Chile*
}

\author{
I Guillermo Caballero Germain** \\ I Diego Pardow***
}

RESUMEN. Este trabajo analiza las prácticas de constitución y administración en sociedades por acciones en Chile. Los datos sugieren que una sociedad por acciones promedio tiene pocas modificaciones al régimen legal dispositivo, destacando el reemplazo del directorio por una administración convencional y la eliminación del juez como mecanismo para designar un árbitro. Resulta llamativo el que ciertas innovaciones (acciones preferentes o dividendos especiales) reciban poca aplicación práctica. Desde el análisis económico del derecho, ambas circunstancias son consistentes con una búsqueda de reglas sencillas. Con todo, una marcada preferencia hacia la administración convencional plantea problemas dogmáticos sobre la aplicación supletoria de las reglas sobre sociedades anónimas.

PALABRAS ClAVE: sociedades por acciones, gobierno corporativo, derecho dispositivo.

* Fecha de recepción: 22 de mayo de 2019. Fecha de aceptación: 30 de marzo de 2020.

Para citar el artículo: Caballero Germain, G. y Pardow, D., "Cuanto más simple, mejor: análisis de las prácticas sobre la constitución y las formas de administración de las sociedades por acciones en Chile", Revista de Derecho Privado, n. ${ }^{\circ} 39$, julio-diciembre 2020, 301-321, Dor: https://doi. org/10.18601/01234366.n39.12.

Los autores agradecen los valiosos comentarios de los profesores Cándido Paz, Jesús Alfaro, Nuria Bermejo, Osvaldo Lagos y los demás participantes del seminario para la discusión de un borrador previo de este trabajo organizado en la Facultad de Derecho de la Universidad Autónoma de Madrid.

** Universidad de Chile, Santiago de Chile, Chile; profesor de Derecho Comercial. Doctor en Derecho, Universidad Autónoma de Madrid, Madrid, España. Abogado, Pontificia Universidad Católica de Valparaíso, Valparaíso, Chile. Contacto: gcaballero@derecho.uchile.cl. Orcid: 0000-0002-9538-3029.

*** Universidad de Chile, Santiago de Chile, Chile; profesor de Derecho Económico. Doctor en Derecho, Universidad de California, Berkeley, Estados Unidos. Magíster en Derecho, Universidad de California, Berkeley, Estados Unidos. Abogado, Universidad de Chile, Santiago de Chile, Chile. Contacto: dpardow@derecho.uchile.cl. Orcid: 0000-0001-6537-4378. 


\title{
Less is More: Analysis of The Practices on the Incorporation and Corporate Governance of Limited Liability Companies in Chile
}

\begin{abstract}
This paper reviews the practices on the incorporation and corporate governance of a type of corporation named "sociedades por acciones" in Chile. Our data suggests that an average "sociedad por acciones" has very few clauses amending the bylaws proposed by the legislator, noticeably the replacement of a board of directors by a structure of conventionally delegated management and simplification of the mechanism for dispute resolution. It also interesting that several innovations introduced by the legislation, such as shareholding preferences and special regimes for paying dividends, had a rather small impact in the respective business practices. From the approach of the economic analysis of the law, both of these trends are consistent with the idea of simplifying the rules governing a corporation. Nevertheless, this strong preference for a conventionally delegated management poses several conceptual problems related with deciding which type of rules should be applied by default to the "sociedades por acciones".
\end{abstract}

KEYWORDS: limited liability company, corporate governance, default rules

Sumario: Introducción. I. Orden público y libertad contractual en materia societaria. II. ¿Cómo usan su libertad contractual nuestros emprendedores? III. Los problemas de una administración convencional. Conclusiones. Referencias.

Aquel cuyo ojo mira hacia abajo en el abismo se marea. Pero ¿cuál es el motivo de esto? [...] La ansiedad es el vértigo de la libertad, que surge cuando el espíritu desea saltar al vacío y la libertad mira hacia sus propias posibilidades, aferrándose a su naturaleza finita.

La libertad sucumbe ante el mareo.

Soren KierkegaARD. El concepto de ansiedad

\section{Introducción}

Hace poco más de una década Chile estableció un régimen legal separado para las sociedades por acciones, cuya principal característica es la libertad que se entrega a las partes para organizar jurídicamente una empresa. Este trabajo analiza cerca de 1700 escrituras públicas donde se recoge la manera en que las partes han utilizado esta libertad. Aunque las modificaciones introducidas por las partes son más bien escasas, se aprecia una tendencia a simplificar la burocracia dentro de la empresa: reemplazar al directorio por una administración convencional entregada directamente a una o más personas, establecer mecanismos más baratos de comunicación con 
los accionistas y hacer más expedito el mecanismo de solución de controversias. También resulta llamativo que las preferencias accionarias, los regímenes especiales de dividendos y otras innovaciones introducidas por el legislador hayan recibido tan poca aplicación práctica. Como hubiera esperado Richard Espstein, los emprendedores chilenos buscan reglas simples aun cuando la estructura de sus negocios sea compleja ${ }^{1}$.

En estas circunstancias, el derecho desempeña un papel determinante a la hora de organizar jurídicamente las empresas. En particular, la marcada preferencia de los emprendedores chilenos por una administración convencional plantea un desafío dogmático difícil de resolver. Aunque la Ley de Sociedades Anónimas constituye el régimen jurídico supletorio para las sociedades por acciones, sus reglas sobre gobierno corporativo funcionan sobre un esquema que distingue tres niveles: la junta de accionistas, un directorio colegiado y el gerente general. La práctica comercial que se observa en materia de sociedades por acciones apunta a concentrar estos últimos dos niveles utilizando la figura de uno o más administradores convencionales. El problema es que esta figura solamente está regulada en el Código Civil a propósito de la sociedad colectiva, revelando así cierto grado de incompatibilidad entre el régimen supletorio escogido por el legislador y la práctica mercantil. A ello se agrega una tendencia interesante en la interacción entre la actividad legislativa y la práctica forense. Durante décadas, muchos estatutos de sociedades de responsabilidad limitada en Chile han establecido un directorio colegiado como mecanismo de administración, acercando esta figura societaria a una lógica de funcionamiento por mayoría que resulta propia de las sociedades de capital ${ }^{2}$. La incorporación del administrador delegado en una sociedad por acciones, por su parte, pareciera acercar esta otra figura societaria a una lógica de delegación que es propia de las sociedades de personas. Utilizando una antigua metáfora del realismo jurídico, el derecho en acción pareciera empeñarse en desdibujar esas diferencias conceptuales entre sociedades de personas y sociedades de capital que con tanto ahínco construye el derecho en los libros ${ }^{3}$.

En definitiva, nuestro objetivo es doble. En primer lugar, buscamos documentar cuál es la práctica mercantil durante la última década en materia de constitución de una sociedad por acciones, situándola en un contexto analítico que permita entender la racionalidad actual de los emprendedores chilenos y el lugar que ocupa este fenómeno dentro la evolución del derecho societario, especialmente dentro de Latinoamérica. En segundo lugar, queremos mostrar que esta práctica mercantil revela

1 Epstein, R., Simple Rules for A Complex World, Cambridge-London, Harvard University Press, 2009.

2 CunEo, A., "El directorio como una forma de administración y representación de la sociedad colectiva", Revista Chilena de Derecho, vol. 13, n. . 3, 1986, 453-462; RioseCo EnRíQuez, G., "La administración de las sociedades de personas", Revista de Derecho de la Universidad de Concepción, n. ${ }^{\circ}$ 187, 1990, 12-13.

3 Pound, R., "Law in books and law in action", American Law Review, n. ${ }^{\circ} 44,1910,12-36$. 
lecciones importantes en materia de política pública y acarrea desafíos dogmáticos importantes. Especialmente, la incorporación de un modelo de administración convencional pareciera reflejar una tendencia interesante: nuestros emprendedores buscan construir un espacio intermedio entre las sociedades de personas y las sociedades de capital, que complemente el catálogo de estructuras de organización empresarial ofrecidas por el legislador. Atendido que países como Colombia, Perú o Argentina han establecido reformas similares en los últimos años, ambos tópicos parecen relevantes en el contexto de nuestra región ${ }^{4}$. Además, aquellos otros países donde la incorporación de un régimen legal para sociedades por acciones aún se está estudiando pueden extraer enseñanzas valiosas para fomentar el emprendimiento a través de reglas dispositivas y elegir un régimen jurídico supletorio que resulte funcional a sus propias tradiciones ${ }^{5}$.

Las sucesivas secciones de este trabajo están organizadas de la siguiente manera. La primera sección describe los objetivos detrás de la incorporación del régimen de sociedades por acciones, mostrando la manera en que esta reforma se inserta dentro de un sistema de derecho societario que está constantemente persiguiendo un balance entre el orden público y la libertad contractual. La segunda sección documenta la práctica mercantil desarrollada en Chile durante la última década respecto de la organización de una sociedad por acciones, analizando sus tendencias principales desde la perspectiva del análisis económico del derecho y la función que cumple el derecho dispositivo en la organización jurídica de una empresa. La tercera sección se enfoca en el principal desafío dogmático que genera la referida práctica mercantil, consistente en sustituir un directorio que funciona colectivamente y por mayoría, por una administración convencional que funciona delegando atribuciones a distintos individuos. La cuarta y última sección sintetiza las conclusiones.

4 En Colombia, la Ley 1258, "[p]or medio de la cual se crea la sociedad por acciones simplificada", publicada en el Diario Oficial el 5 de diciembre de 2008, para lo cual se tuvo en consideración la experiencia en la materia de países como Estados Unidos de América, Inglaterra, Francia, España, Brasil y Chile (vid. REYES, F., SAS La sociedad por acciones simplificada, 3. a ed., Bogotá, Legis, 2015, 60-87). En Argentina, la Ley 27.349, sobre apoyo al capital emprendedor, publicada en el Boletín Oficial el 12 de abril de 2017, introdujo en el título III la sociedad por acciones simplificada (SAS), tomando la experiencia previa de las legislaciones chilena, colombiana, francesa y mexicana, según nos informa Verón, A., "La sociedad por acciones simplificada de la ley 27.349", La Ley, 25 de abril de 2017 (AR/DOC/1027/2017), disponible en [htpps://thomsomreuterslatam.com/2017/04/ la-sociedad-por-acciones-simplificada-de-la-ley-27.349/] [consultado el 2 de mayo de 2019]. En Perú, el Decreto Legislativo 1409 crea la sociedad por acciones cerrada simplificada, que si bien flexibiliza el régimen de la sociedad anónima cerrada, presenta importantes limitaciones, como, por ejemplo, solo pueden ser accionistas personas naturales (artículo 4) y se permiten solo aportes en dinero o bienes muebles (artículo 6).

5 En Brasil se presentó, con fecha 4 de agosto de 2012, un Projeto de Lei n. ${ }^{\circ} 4.303 / 2012$, por parte del Diputado Federal Laércio Oliveira, que "Altera a Lei n. ${ }^{\circ}$ 6.404, de 15 de dezembro de 1976, para criar e disciplinar a sociedade anônima simplificada (SAS)", el cual hasta la fecha no ha sido aprobado; disponible en [www.lexml.gov.br/urn/urn:lex:br:camara.deputados:projeto.lei;pl:2012-08-09;4303] [consultado el 3 de mayo de 2019]. 


\section{Orden público y libertad contractual en materia societaria}

La incorporación del régimen legal de las sociedades por acciones en el ordenamiento jurídico chileno se produce a finales de la década pasada, en el contexto de una política de fomento para el desarrollo de capital de riesgo. De acuerdo con el mensaje presidencial con que se inició la tramitación legislativa, la industria de capital de riesgo consistía en "proyectos de inversión emergentes o sin historia, pero con amplio potencial de crecimiento", como sería el caso del desarrollo de patentes, procesos productivos y nuevas tecnologías ${ }^{6}$. Al carecer de una trayectoria previa, este tipo de proyectos enfrentaba dificultades para levantar financiamiento a través de canales tradicionales como el mercado de valores o los bancos de inversión. Con el fin de crear condiciones para el crecimiento de la industria de capital de riesgo, durante el año 2003 se presentó un conjunto de reformas legales bajo la denominación de "Segunda reforma al mercado de capitales" o "MK2"7.

En lo que ahora interesa respecto de estas reformas, la experiencia extranjera sugería que la industria de capital de riesgo exigía una figura societaria específica que se adecuase a sus necesidades particulares. El diagnóstico del gobierno de la época fue que Chile carecía de un régimen societario lo suficientemente flexible como para servir de vehículo de inversión respecto de este tipo de proyectos ${ }^{8}$. Por una parte, se necesitaba "un tipo social donde la participación de cada socio sea fácilmente transable, de manera de permitir una salida expedita y así se creen los incentivos a participar en la industria de capital de riesgo" ". Esta exigencia suponía que los derechos sociales fueran libremente transferibles, de manera similar a la sociedad anónima ${ }^{10}$.

6 Mensaje Presidencial, Historia de la Ley 20.190, 5, disponible en [www.bcn.cl/historiadelaley/nc/ historia-de-la-ley/5361/] [consultado el 2 de mayo de 2019]. En concordancia con lo anterior, tributariamente "se entenderá que capital de riesgo es aquel capital que se invierte en proyectos que presentan, al momento de efectuar la inversión, una alta expectativa de retorno y alto riesgo" (artículo primero transitorio, 1.iii, Ley 20.190).

7 En concreto, la iniciativa se denominaba "Proyecto de Ley que introduce adecuaciones de índole tributaria e institucional para el fomento de la industria de capital de riesgo y continúa con la modernización del mercado de capitales" y contemplaba tres grandes áreas: capital de riesgo y nuevas formas de financiamiento, seguridad del mercado de valores y desarrollo de los mercados. En cuanto a la industria de capital de riesgo, además de un beneficio tributario, se establecía una autorización para que los organismos públicos encargados del fomento productivo, así como los bancos comerciales, adquirieran cuotas de fondos de inversión en capital de riesgo. A ello se sumaba una nueva ley de prenda sin desplazamiento y la ley sobre sociedades por acciones, esta última como un nuevo vehículo de inversión adaptado a las exigencias de la industria de capital de riesgo. Historia de la Ley 20.190, disponible en [www.bcn.cl/historiadelaley/nc/historia-de-la-ley/5361/1559-1562] [consultado el 2 de mayo de 2019].

8 Historia de la Ley 20.190, 89, disponible en [www.bcn.cl/historiadelaley/nc/historia-de-la-ley/5361].

9 Mensaje Presidencial, Historia de la Ley 20.190, 15, disponible en [www.bcn.cl/historiadelaley/nc/ historia-de-la-ley/5361/] [consultado el 2 de mayo de 2019].

10 La posibilidad de adaptar la sociedad a las necesidades no solo del giro sino de los concretos partícipes tiende a personalizar las relaciones societarias. En cambio, la fluida circulación de los derechos sociales implica despersonalizar la sociedad, facilitándose la sustitución de los integrantes. Esto es lo 
Por otra parte, sin embargo, se buscaba dar flexibilidad para que los emprendedores pudieran adecuarse a los distintos escenarios donde es posible desarrollar la industria del capital de riesgo. La sociedad anónima no cumplía este segundo requerimiento, toda vez que tiene una estructura rígida, pensada para satisfacer el interés público en el mercado de valores ${ }^{11}$. Como quedó constancia en la tramitación legislativa, estas "rigideces [...] sólo pueden ser superadas parcialmente mediante artificiosos contratos o pactos sociales", especialmente en cuanto a "separar los roles y derechos de los distintos tipos de participantes" a través de acciones con voto múltiple, dividendos por unidad de negocio y otros mecanismos semejantes ${ }^{12}$. La solución del legislador consistió en establecer un régimen de sociedades por acciones "liviano y flexible", para que "los inversionistas en capital de riesgo puedan, a través de tecnología contractual más sofisticada, hacer valer directamente sus derechos"13. En definitiva, el objetivo de política pública era "promover nuevos tipos de emprendimiento, combinando algunas características de las sociedades anónimas, en especial su reglamentación, con la flexibilidad que ofrece otro tipo de sociedades, como las sociedades de personas"14.

Como ya es costumbre en la práctica legislativa chilena, el proyecto de ley sobre sociedades por acciones no indica sus fuentes materiales, limitándose a referirse de manera general a la experiencia internacional ${ }^{15}$. Ahora bien: si revisamos el derecho comparado sobre esta materia, encontraremos que el origen de un tipo societario altamente flexible y centrado en la libre transferencia de los derechos sociales suele situarse en Estados Unidos, al establecerse el régimen legal de las denominadas limited liability companies (LLC) en $1977^{[16]}$. Su principal novedad consistía en combinar

que suele denominarse "estandarización" de los derechos societarios, que a su vez facilita su circulación en el mercado de capitales. Véase Armour, J., Hansmann, H., Kraakman, R., Pargendler, M., "What is Corporate Law?", KRAAKMAn, R. et al., The Anatomy of Corporate Law. A Comparative and Functional Approach, 3. a ed., Oxford, Oxford University Press, 2017, 20-22.

11 En términos generales, todas las sociedades que se transan en una bolsa tienen estructuras de gobierno corporativo y derechos políticos similares, porque ello permite que el precio las distintas acciones sean comparables. Enríquez, L., Hertog, G., Kraakman, R., Rock, E., "Corporate Law and Securities Markets", Krankman, R. et al., The Anatomy of Corporate Law. A Comparative and Functional Approach, 3. a ed., Oxford, Oxford University Press, 2017, 245-246. Aunque no emite valores de oferta pública, la sociedad anónima cerrada comparte esta rigidez. Ello generalmente se explica por razones históricas, debido a la desconfianza que generaba este mecanismo de organización empresarial. RIPERT, G., Aspectos jurídicos del capitalismo moderno, Granada, Comares, 2001, 50 y 90.

12 Historia de la Ley 20.190, 89 y 170, disponible en [www.bcn.cl/historiadelaley/nc/historia-de-laley/5361/] [consultado el 2 de mayo de 2019].

13 Mensaje Presidencial, Historia de la Ley 20.190, 16, disponible en [www.bcn.cl/historiadelaley/nc/ historia-de-la-ley/5361/] [consultado el 2 de mayo de 2019].

14 Idem.

15 De hecho, Jara sostiene que "[1] as sociedades por acciones chilenas no son entonces una forma novedosa que demuestre la creatividad legislativa nacional, sino que simplemente son un compendio de proyectos legislativos foráneos, reducidos y sistematizados". JARA, A., "Sociedad por acciones. Ley 20.190", Revista Chilena de Derecho, vol. 34, n. ${ }^{\circ} 2,382$.

16 Geu, T., "Understanding the Limited Liability Company: A Basic Comparative Primer (Part One)", South Dakota Law Review, 37, 1992, 50; críticamente, CARnEY, W., "Limited Liability Companies: 
elementos de los dos modelos tradicionales de para entregar estructura jurídica a una empresa: la sociedad anónima (corporation) y la sociedad personalista (partnership). De manera similar a la sociedad personalista, daba bastante libertad a las partes para organizar el gobierno corporativo y mecanismos de transferencia de los derechos sociales. No obstante, extendía también ciertas características que hasta ese momento eran privativas de la sociedad anónima, como la limitación de responsabilidad y una personalidad jurídica distinta a la de sus miembros ${ }^{17}$. Las razones detrás del surgimiento de la LLC fueron de origen tributario y buscaron sujetar a la LLC al régimen tributario de las sociedades de personas (single tax) y evitar el de las sociedades anónimas (double tax).

Algunas décadas después, la Ley 94-1 de 1994 introdujo en Francia la société par actions simplifiée (SAS), un nuevo tipo societario sujeto supletoriamente a las normas de la sociedad anónima, pero con la importante exclusión de sus reglas sobre gobierno corporativo y caracterizada por una amplia libertad contractual ${ }^{18}$. En el caso del Reino Unido, la limited liability partnership (LLP) se creó recién en el 2000 con la finalidad de extender la limitación de responsabilidad a las sociedades de profesionales y otros negocios similares. Al igual que en los casos anteriores, esta limitación acerca a la LLP a una sociedad anónima, aunque tributariamente siga el régimen de las sociedades de personas (single tier taxation) ${ }^{19}$. Como se aprecia, las características de este nuevo tipo societario simplificado, en los países que Chile suele utilizar como referencia, serían: (1) la limitación de responsabilidad de los miembros por las deudas sociales; (2) la flexibilidad para configurar la estructura interna de gobierno y administración; y (3) un régimen tributario de un escalón ${ }^{20}$.

Con todo, es posible observar una tendencia similar, tanto en el ámbito latinoamericano como en Asia y Medio Oriente. También durante la primera década del

Origins and Antecedents", University of Colorado Law Review, vol. 66, 1995, 858-868; RIBSTEIN, L., The Rise of the Uncorporation, New York-Oxford, Oxford University Press, 2010, 99-101 y 119-121.

17 En Estados Unidos la sociedad personalista se caracterizó originalmente por ser una sociedad puramente obligacional, carente de personalidad jurídica. Esta característica fue incorporada en la Uniform Partnership Act de 1997 y en la Uniform Limited Liability Company Act de 2006, para cada uno de estos tipos societarios.

18 Con todo, sus reglas originales eran bastante restrictivas: solo podían constituirla sociedades con un capital superior a doscientos mil euros y que comprometieran un aporte mínimo de cincuenta mil euros. Muchas de estas trabas fueron eliminadas cinco años después, con la Ley 99-587 de 1999, destinada a fomentar la innovación tecnológica. Posteriormente, el régimen legal de la sas ha sido objeto de cambios sucesivos, entre los que se destacan la Ley 2001-412 de 2001 (sobre transformación y convenios con accionistas principales), la Ley 2003-706 de 2003 (reformando algunos aspectos del gobierno corporativo), la Ley 2008-776 de 2008 (eliminando la exigencia de capital mínimo y autorizando aportes en industria) y la Ley 2009-80 de 2009 (facilitando un acceso limitado al mercado de valores).

19 Whittaker, J. y Machell, J., The Law of Limited Liability Partnerships, Bloomsbury Professional, 3. ${ }^{\text {a }}$ ed., 2009, 1-13 y 391-405. La Limited Liability Partnership Act rige también en Irlanda del Norte a partir del año 2009.

20 Whittaker, J. y Machell, J., The Law of Limited Liability Partnerships, Bloomsbury Professional, 3. ${ }^{\text {a }}$ ed., 2009, 392. 
siglo XXI, Japón, Singapur, Dubai o Katar llevaban adelante procesos similares al de Chile $^{21}$. En los años siguientes, a su vez, este modelo de sociedad simplificada se incorporó en Argentina, Colombia, México y Perú ${ }^{22}$. En el campo regional, un hito relevante es la Ley Modelo sobre Sociedad por Acciones Simplificada, aprobada por el Comité Jurídico Interamericano de la Organización de los Estados Americanos (oEA $)^{23}$. Así también, la Comisión de Naciones Unidas para el desarrollo del Derecho Mercantil Internacional (CNUDMI) está preparando una Guía Legislativa sobre Entidades de Responsabilidad Limitada, que recoge las ideas fundamentales antes descritas ${ }^{24}$. Es posible, sin embargo, reconocer dos grandes modelos de sociedades simplificadas: uno más cercano a la sociedad de capital, y otro estructurado sobre la base de la sociedad de personas ${ }^{25}$. Las diferencias principales entre ambos se materializan en la manera de transferir los derechos sociales, así como en la organización del gobierno corporativo. En cuanto a la transferencia de derechos, la división del capital en acciones suele llevar aparejado un régimen de transferencia de los derechos sociales relativamente expedito. Con todo, algunos ordenamientos establecen la posibilidad de transferir solamente los derechos económicos y retener los políticos, siguiendo la lógica de las sociedades de personas ${ }^{26}$. Por otra parte, tratándose del gobierno corporativo, el modelo personalista entrega poderes de representación separados a cada socio, mientras el modelo capitalista se basa en entregar la administración a un directorio ${ }^{27}$.

21 Véase, por ejemplo, la Limited Liability Partnerships Act de 2005 para Japón; la Limited Liability Partnerships Act de 2005 para Singapur, la Ley 5 de 2004 para Dubai o la Limited Liability Partnerships Regulations de 2005 para Katar.

22 Véase, por ejemplo, Ley 1258 de 2008 para Colombia; Decreto del 14 de marzo de 2016 para México; Decreto Legislativo 1409 de 2018 para Perú. Cabe destacar que pese a la influencia inicial de la legislación chilena en estas reformas, el modelo colombiano es el que suele considerarse como referencia en foros internacionales. REYES, F., SAS La sociedad por acciones simplificada, 3. ad., Bogotá, Legis, 2015, 81 .

23 Organización de los Estados Americanos, "Recomendaciones sobre la propuesta de proyecto de Ley Modelo sobre Sociedad por Acciones Simplificada", aprobado el 9 de marzo de 2012, disponible en [www.oas.org/es/sla/ddi/docs/Ley_Modelo_sobre_la_Sociedad_Acciones_Simplificada.pdf] [consultado el 3 de mayo de 2019].

24 Comisión de Naciones Unidas para el desarrollo del Derecho Mercantil Internacional, Proyecto de guía legislativa sobre una entidad de responsabilidad limitada (A/CN.9/WG.I/WP.114), disponible en [https://undocs.org/es/A/CN.9/WG.I/wP.114]. Por otra parte, entre los países que también han incorporado este tipo societario en los últimos años podemos encontrar a Emiratos Árabes Unidos (Public and Private Joint Stock Co, 2013), India (Limited Liability Partnership Act, 2008), Nueva Zelandia (New Zealand Limited Partnership Act 2008), Sudáfrica (Companies Act 2008).

25 Whittaker, J., Machell, J., The Law of Limited Liability Partnerships, Bloomsbury Professional, 3. ${ }^{\mathrm{a}}$ ed., 2009, 391-405.

26 Así, por ejemplo, sucede en la llp inglesa (s. 7(2) Llp Act 2000). WhitTAKER, J., MACHELl, J., The Law of Limited Liability Partnerships, Bloomsbury Professional, 3. a ed., 2009, 107.

27 Un ejemplo del primer caso es la sección 407 de la Uniform Limited Liability Company Act (2006). National Conference of Commissioners on Uniform State Laws (2014), Uniform Limited Liability Company Act (2006, Last Amended 2013) with prefatory note and comments, disponible en [www.uniformlaws.org/viewdocument/final-act-with-comments-109?CommunityKey=bbea059c- 
A diferencia de lo que sucedía en Estados Unidos, Francia o el Reino Unido, Chile contaba desde hacía muchos años con un tipo de sociedad personalista dotada de personalidad jurídica y limitación de responsabilidad. Las sociedades de responsabilidad limitada (SRL) se incorporaron en 1923 y se utilizaron ampliamente al momento de legislar sobre la materia. Desde esta perspectiva, el legislador chileno podría haber simplificado la transferencia de derechos sociales de una SRL y construir un tipo societario con orientación personalista ${ }^{28}$. No obstante, el nuevo párrafo del Código de Comercio donde se establece el régimen de las sociedades por acciones sigue claramente una orientación capitalista ${ }^{29}$. Siguiendo la clasificación anteriormente expuesta, el capital se divide en acciones libremente transferibles y existe un directorio encargado de administrar la sociedad. Más aún, el artículo 424 del Código de Comercio establece que "las normas aplicables a las sociedades anónimas" se aplican con carácter supletorio. Con todo, las partes cuentan con amplia libertad para establecer reglas diferentes y la propia legislación sugiere algunas variaciones a esta estructura. La siguiente sección analiza la manera en que los emprendedores chilenos han utilizado esta libertad.

\section{II. ¿Cómo usan su libertad contractual nuestros emprendedores?}

Según vimos en la sección anterior, el régimen de las sociedades por acciones da mayor libertad contractual a las partes, especialmente cuando lo comparamos con la sociedad anónima. Una de las maneras en que se materializa esta libertad consiste en establecer un conjunto de cláusulas donde la ley propone una regla por defecto, pero se permite explícitamente que las partes modifiquen su contenido. El régimen legal de las sociedades por acciones establece dieciséis de estas cláusulas y su contenido abarca desde aspectos relativamente triviales, como la forma de comunicación con los accionistas, hasta aspectos determinantes para el funcionamiento de una compañía como la estructura de gobierno corporativo, la manera de repartir utilidades o los mecanismos de transferencia de las acciones.

6853-4f45-b69b-7ca2e49cf740\&tab=librarydocuments] [consultado 5 de mayo de 2019]. Un ejemplo del segundo caso puede encontrarse en la legislación peruana, donde, por aplicación supletoria de las normas de la sociedad anónima cerrada, la representación recae en un directorio. MAQUERA, C., "La sociedad por acciones cerrada simplificada: nuevo régimen societario alternativo y su estudio comparativo con las sociedades por acciones simplificadas de Colombia, México y Argentina", 14, disponible en [https://docplayer.es/109283224-La-sociedad-por-acciones-cerrada-simplificada. html] [consultado el 3 de mayo de 2019].

28 De hecho, la práctica contractual ya había iniciado este camino incorporando en el estatuto de las SRL una autorización previa y general de todos los socios para enajenar los derechos sociales. CABALLERO, G., "Comentario de jurisprudencia. Prescripción adquisitiva y cesión del derecho de participación en una sociedad de responsabilidad limitada", Revista Chilena de Derecho Privado, n. ${ }^{\circ}$ 20, 2013, 267.

29 De hecho, originalmente las sociedades por acciones debían regularse dentro de una sección específica de la Ley de Sociedades Anónimas (Historia de la Ley 20.190, pp. 15 y 48). Véase Prado, A., Aspectos comerciales de las sociedades por acciones, Santiago, Cámara de Comercio de Santiago, 2007, 4; Sandoval, R., "Sociedad por acciones", Revista de Derecho de la Universidad de Concepción, n. ${ }^{\circ} 221-222,2007,8$. 
Para efectos de analizar la manera en que los emprendedores chilenos utilizan esta mayor libertad contractual, desarrollamos una base de datos inédita con casi 1700 escrituras públicas de constitución de sociedades por acciones otorgadas entre inicios del 2016 y mediados del 2018. Cerca de un $90 \%$ de estas escrituras se obtuvo mediante convenios de colaboración con las principales notarías de la ciudad de Santiago ${ }^{30}$. El 10\% restante corresponde a sociedades por acciones constituidas a través del programa de fomento empresarial denominado "Empresas en un día", donde el empresario accede a una plataforma electrónica que facilita el proceso de redacción de la escritura y los trámites posteriores ${ }^{31}$. Salvo en aquellos casos en que se indica lo contrario, nuestro análisis se enfoca en las tendencias de estos dos grupos de empresas conjuntamente ${ }^{32}$.

La base de datos se construyó mediante una revisión estructurada de estas dieciséis cláusulas donde las partes pueden ejercer su libertad contractual de manera más intensa. Para cada una de las 1700 escrituras incorporadas en nuestro análisis, alguno de los miembros de nuestro equipo de investigación debía responder un cuestionario dirigido a determinar si los contratantes establecieron reglas específicas en este grupo de dieciséis cláusulas, o bien descansaron en el contenido dispositivo propuesto por el legislador ${ }^{33}$. La tabla 1 muestra los resultados generales de este análisis, con las filas reflejando cada una de las cláusulas susceptibles de modificarse y el porcentaje representando la proporción de sociedades por acciones donde los contratantes establecieron reglas diferentes de las establecidas por el legislador. El número entre paréntesis, por su parte, indica la cantidad de sociedades por acciones en nuestra base de datos en las que los socios efectivamente acordaron modificar el contenido dispositivo de la cláusula respectiva. En términos generales, el promedio de las empresas cambia entre cuatro y cinco cláusulas del estatuto propuesto por el legislador. Lo más interesante, sin embargo, es que las variaciones alrededor de este promedio

30 En particular, las notarías de Eduardo Avello Concha, Hernán Cuadra Gazmuri, Eduardo Díez Morello, Cosme Gomila Gatica, Félix Jara Cadot, Alfredo Martin Illanes, Antonieta Mendoza Escalas, Jorge Ossa, Valeria Ronchera Flores, Humberto Santelices Narducci y Patricio Zaldívar Mackenna facilitaron copias electrónicas de aproximadamente 1500 escrituras de constitución de sociedades por acciones. Ello corresponde a la totalidad de escrituras de este tipo celebrados en cualquiera de las seis notarías referidas, entre enero de 2016 y septiembre de 2017. Es importante destacar que no se realizó ningún procedimiento de muestra aleatoria, sino que se analizaron la totalidad de los documentos relevantes respecto de todas aquellas notarías que estuvieron dispuestas a facilitar sus registros.

31 El registro de empresas y sociedades está disponible en [www.tuempresaenundia.cl].

32 Es importante tener en cuenta que nuestro procedimiento de recolección de datos nunca tuvo por objetivo realizar una muestra aleatoria, sino simplemente obtener la mayor cantidad de información disponible. De este modo, nuestro enfoque descansa en las razones cualitativas explicadas más adelante para extender las tendencias observadas en nuestra base de datos a una población más general. En cualquier caso, la base de datos y los protocolos de codificación pueden ser solicitados a los autores.

33 Los miembros del equipo de investigación fueron los memoristas Camilo Arriaza Mora, Valentina Barros Sanfuentes, Valeria Bazáez Carvajal, Claudia Cifuentes Cockbaine, Víctor Contreras Kong, Felipe Gianelli O’Ryan, Ana Belén Macaya Cerna, Daniel Puente Alfaro, Camila Román Mora, Leonor Venegas Cruz y Jaime Zavala Vuletich, a quienes agradecemos su colaboración en este proyecto de investigación. 
siguen una distribución relativamente simétrica y con forma de campana, similar a la distribución normal ${ }^{34}$.

Tabla 1. Utilización promedio de las cláusulas dispositivas en una sociedad por acciones

\begin{tabular}{|l|c|c|}
\hline \multicolumn{1}{|c|}{ Tipo de cláusula } & Utilización & $\left(\right.$ n. ${ }^{\circ}$ \\
\hline Establecer que los títulos de las acciones serán desmaterializados & $85,1 \%$ & $(1445)$ \\
\hline Delegar la administración social en una sola persona & $84,5 \%$ & $(1437)$ \\
\hline Establecer reglas especiales en materia de arbitraje & $58,2 \%$ & $(990)$ \\
\hline Incorporar un mecanismo de comunicación diferente a la carta certificada & $45,1 \%$ & $(767)$ \\
\hline Incorporar el derecho de adquisición preferente para aumentos de capital & $36,9 \%$ & $(628)$ \\
\hline Disminuir el quórum de unanimidad para reducir el capital de la sociedad & $33,1 \%$ & $(564)$ \\
\hline Aumentar el plazo de un año para enajenar acciones de propia emisión & $21,1 \%$ & $(358)$ \\
\hline Establecer un plazo diferente a cinco años para el pago de los aportes & $17,7 \%$ & $(302)$ \\
\hline Permitir que un aumento de capital sea aprobado por el Directorio & $12,1 \%$ & $(206)$ \\
\hline Disolución de la sociedad por reunión de las acciones en una persona & $4,3 \%$ & $(73)$ \\
\hline Permitir el pago de dividendos por unidad de negocios & $2,1 \%$ & $(35)$ \\
\hline Incorporar opciones de compra o venta & $1,1 \%$ & $(18)$ \\
\hline Establecer mecanismos de voto múltiple u otras preferencias & $0,6 \%$ & $(11)$ \\
\hline Establecer la obligación de pagar un dividendo fijo & $0,6 \%$ & $(10)$ \\
\hline Prohibir que la sociedad tenga acciones de propia emisión & $0,5 \%$ & $(8)$ \\
\hline Restringir los porcentajes mínimos o máximos de propiedad accionaria & $0,1 \%$ & $(2)$ \\
\hline Promedio & $\mathbf{2 7 , 2 \%}$ & $(\mathbf{4 2 8})$ \\
\hline
\end{tabular}

Fuente: elaboración propia sobre la base de información pública sistematizada para este trabajo.

Como muestra la figura 1, cerca de dos tercios de las empresas cambian entre tres y seis cláusulas, mientras que el $95 \%$ de las empresas se ubica en un rango que oscila entre dos y siete modificaciones. El primer grupo de empresas situadas fuera de este rango corresponde a 35 sociedades donde solo se modifica el estatuto propuesto por el legislador para establecer que los títulos serán desmaterializados, esto es, liberar

34 Nuevamente, nuestra aproximación a los datos se sostiene en una interpretación esencialmente cualitativa, sin que sea nuestra intención realizar un estudio cuantitativo con muestras aleatorias y test de significancia estadística. Ahora bien: para facilitar el diálogo con otras ciencias sociales, el análisis de los datos en esta sección utiliza los umbrales tradicionales de ese tipo de estudios, como ocurre con el parámetro del $95 \%$ para identificar las tendencias centrales. 
a la sociedad por acciones de la necesidad de imprimir los títulos correspondientes. Cerca del $85 \%$ de las sociedades establece este tipo de cláusulas, pero lo interesante es el $15 \%$ de sociedades donde los socios prefieren títulos materializados corresponde a una sociedad por acciones que tienen varias otras modificaciones. Con todo, es importante tener en cuenta que las sociedades con numerosas modificaciones son bastante heterogéneas. Efectivamente existe un grupo de 39 sociedades que tienen más de siete modificaciones, pero es difícil encontrar una tendencia clara respecto de la manera de construir estos estatutos ${ }^{35}$.

Figura 1. Frecuencia de utilización de las cláusulas dispositivas de una sociedad por acciones

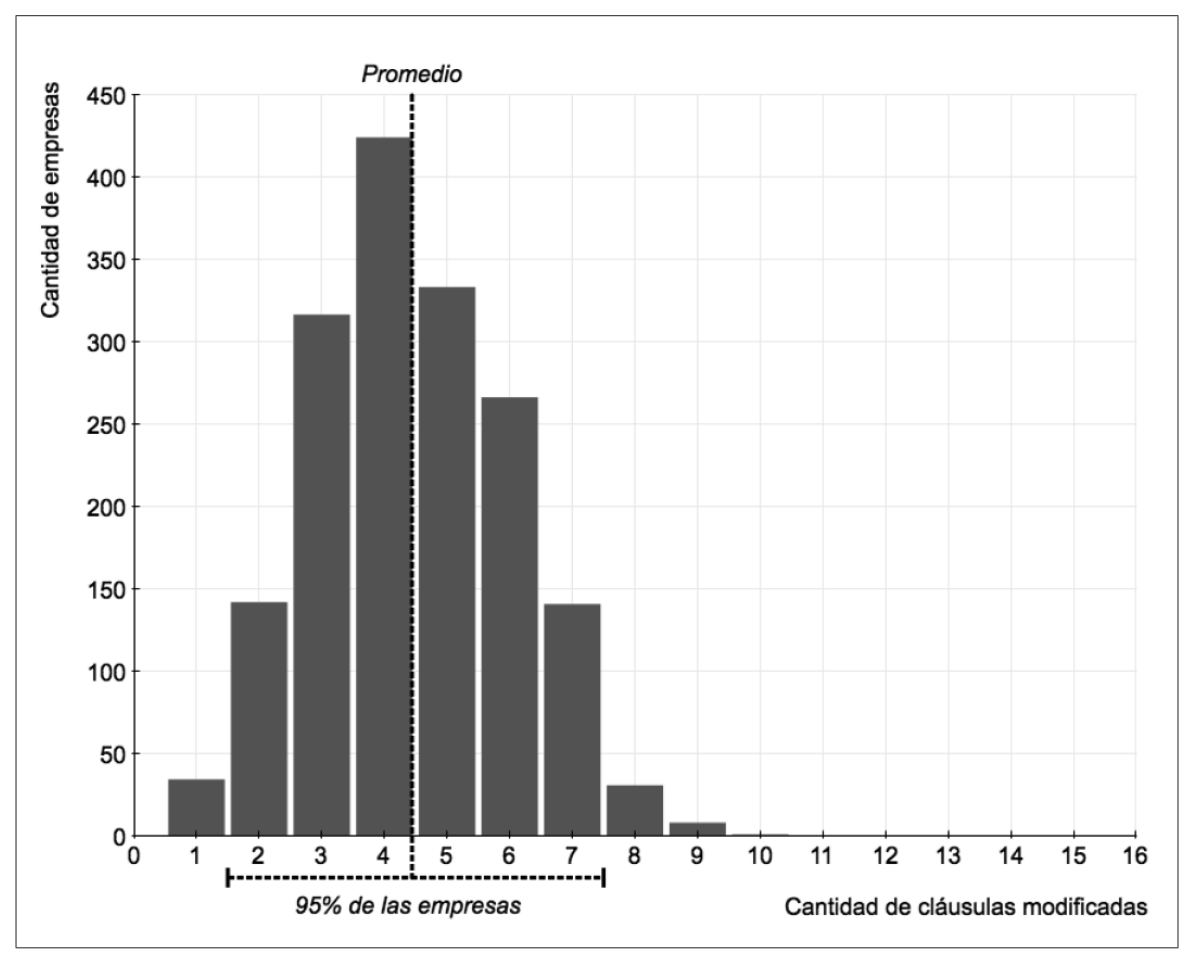

Fuente: elaboración propia sobre la base de información pública sistematizada para este trabajo.

De aceptarse que nuestra base de datos resulta ilustrativa respecto de la manera en que se constituye una sociedad por acciones en Chile, el estatuto social típico se caracterizaría entonces por descansar significativamente en las reglas propuestas por el le-

35 En otras palabras, estas 39 sociedades muestran patrones de modificaciones muy diferentes entre sí. La única particularidad es que todas ellas utilizan alguna de las reglas para establecer formas de reparto de dividendos que se apartan del sistema utilizado en las sociedades anónimas. 
gislador, estableciendo tres grupos de modificaciones o reglas convencionales. Junto con la desmaterialización de los títulos, la generalidad de los estatutos de sociedades por acciones acentúa esta menor dependencia de los soportes físicos estableciendo mecanismos de comunicación electrónicos entre la empresa y sus accionistas, ya sea la publicación en medios de comunicación digital, el uso del correo electrónico o algún otro mecanismo análogo. Enseguida, también es bastante frecuente que los accionistas simplifiquen el mecanismo de arbitraje de controversias, particularmente en lo que dice relación con el nombramiento de jueces-árbitros ${ }^{36}$. Finalmente, resulta llamativa la tendencia a modificar el sistema de gobierno corporativo establecido dispositivamente, con más del $80 \%$ de las sociedades estableciendo un modelo de administración convencional. Este tipo de modificación es claramente la más importante desde una perspectiva dogmática, por lo que su discusión particular se realizará en la sección siguiente.

Con todo, también es posible construir una racionalidad que explique conjuntamente estas tendencias de los emprendedores chilenos. Para ello, aproximémonos a la evidencia referida más arriba desde el análisis económico del derecho, donde de las reglas supletorias de un contrato tiene como finalidad principal disminuir los costos de transacción y fomentar el emprendimiento ${ }^{37}$. Atendido que negociar explícitamente respecto de todas las posibles contingencias de un negocio resultaría excesivamente costoso, el legislador debe hacer el ejercicio hipotético de ponerse en el lugar de las partes y recoger la manera en que razonablemente habrían organizado jurídicamente su empresa ${ }^{38}$. Ahora bien: como resulta imposible atender a las necesidades particulares de cada negocio, las reglas supletorias tienden a recoger aquello que la mayoría de los contratantes hubiera acordado en circunstancias similares ${ }^{39}$.

36 En términos generales, la regla por defecto en el derecho chileno establece que son los tribunales quienes designan a los árbitros a través de un procedimiento abreviado. En el caso de la sociedades por acciones, todas las modificaciones a las reglas de arbitraje apuntan a simplificar este mecanismo, ya sea entregándole atribuciones a la Cámara de Comercio de Santiago para realizar el nombramiento o estableciendo un procedimiento donde las partes interactúan directamente.

37 Posner, R., Economic Analysis of Law, Little, Brown and Company, 3. a ed., 1986, 372; Goetz, $\mathrm{CH}_{\mathrm{H}}$ y Sсотт, R., "The Limits of Expanded Choice: An Analysis of the Interactions Between Express and Implied Contract Terms", California Law Review, vol. 73 , n. ${ }^{\circ}$ 2, 1985, 262 y 265; EASTERBrook, F. y Fischel, D., The Economic Structure of Corporate Law, Cambridge-London, Harvard University Press, 1991, 35; Armour, J., Hansmann, H., Kraakman, R. y Pargendler, M., "What is Corporate Law?", Krankman, R. et al., The Anatomy of Corporate Law. A Comparative and Functional Approach, 3. ${ }^{a}$ ed., Oxford, Oxford University Press, 2017, 18.

38 Schwartz, A., "Proposals for Products Liability Reform: A Theoretical Synthesis", Yale Law Journal, vol. 97, n. ${ }^{\circ}$ 3, 1988, 361; BAIRD, D. y JACKSON, T., "Fraudulent Conveyance Law and Its Proper Domain", Vanderbilt Law Review, vol. 38, Issue 4, 1985, 836; EASTERBrooK, F. y Fischel, D., The Economic Structure of Corporate Law, Cambridge-London, Harvard University Press, 1991, 35; Posner, R., Economic Analysis of Law, Little, Brown and Company, 3. a ed., 1986, 372; GoETz, CH. y Sсотт, R., "The Mitigation Principle: Toward a General Theory of Contractual Obligation", Virginia Law Review, vol. 69, Issue 6, 1983, 971.

39 Ayres y Gertner distinguen entre tailored defaults y untailored defaults. Las primeras son aquellas que las partes concretas habrían acordado ex ante ("reasonable in the circumstances") y suponen 
Desde esta perspectiva, la incorporación de una cláusula particular como regla supletoria suele verse como la culminación de un proceso de maduración de una práctica mercantil ${ }^{40}$.

Una rama más reciente de la literatura señala que en lugar de recoger una práctica existente, muchas reglas supletorias contribuyen a crearla ${ }^{41}$. En concreto, sería importante distinguir aquellos casos en que una regla opera por defecto y a menos que las partes expresamente acuerden algo distinto (opt-out), de aquellos donde es necesaria una voluntad común explícita para incorporar esa regla en la relación contractual (opt-in). Siguiendo el razonamiento de Thaler y Sunstein, las partes de un contrato tienden a seguir irracionalmente la regla establecida por defecto, por lo que es posible fomentar ciertas formas de organización empresarial utilizando el contenido dispositivo de la legislación societaria ${ }^{42}$. Desde esta perspectiva, las cuatro cláusulas donde la incorporación de modificaciones supera el $40 \%$ parecieran seguir la tradicional racionalidad de disminuir los costos de transacción, antes que una persistencia irreflexiva en la utilización de las reglas por defecto. Tanto la desmaterialización de los títulos como el administrador unipersonal, la simplificación del arbitraje y el establecimiento de mecanismos de comunicación más directos apuntan a disminuir la burocracia en el interior de la empresa. En definitiva, la principal tendencia entre los emprendedores chilenos pareciera ser la búsqueda de reglas simples, incluso si ello implica modificar un derecho dispositivo que hace más compleja la organización y funcionamiento de una sociedad por acciones.

Esta tendencia pareciera confirmarse cuando miramos la otra cara de la moneda. Existen cinco tipos de cláusulas que se utilizan en muy pocos casos, cerca de 15 sociedades en promedio, representando el $1 \%$ del total. Estos cinco tipos de cláusulas contienen reglas relativamente complejas sobre regímenes especiales de dividendos y restricciones a la transferencia de acciones, configuradas como cláusula del tipo opt-in. Esto es, cláusulas donde la ley sugiere un contenido, pero exigiendo que los accionistas elijan incorporarlo expresamente. La función de estas reglas opt-in, sin embargo, consiste en dar certeza jurídica acerca de la licitud de ciertos mecanismos

un costo ex post para los tribunales al deber determinar la situación caso a caso. Las untailored defaults corresponden a un estándar representativo de lo que la mayoría de todos los contratantes habría acordado ex ante. Ayres, I., GerTnER, R., "Filling gaps in incomplete contracts: An economic theory of default rules", The Yale Law Journal, vol. 99, 1989, 87-130. Véase también GoETz, Сн. у Scotт, R., “The Mitigation Principle: Toward a General Theory of Contractual Obligation", Virginia Law Review, vol. 69, Issue 6, 1983, 971.

40 Goetz, Сн. у Sсотт, R., "The Limits of Expanded Choice: An Analysis of the Interactions Between Express and Implied Contract Terms", California Law Review, vol. 73, n. . 2, 1985, 278.

41 Thaler, R. y Sunstein, C., Nudge. Improving decisions About Health, Wealth, and Happiness, New Haven-London, Yale University Press, 2008, passim, especialmente 12, 35 y 83-87. Una idea sugerida también por Ayres y Gertner a fin de lograr la revelación de información entre partes contratantes con asimetrías de información. Ayres, I. y Gertner, R., "Filling gaps in incomplete contracts: An economic theory of default rules", The Yale Law Journal, vol. 99, 1989, 107.

42 Thaler, R. y Sunstein, C., Nudge. Improving decisions About Health, Wealth, and Happiness, New Haven-London, Yale University Press, 2008, 83-87. 
que resultan novedosos en el tráfico mercantil, y por lo tanto, sujetos a un escrutinio jurisdiccional que puede resultar riesgoso. Así, por ejemplo, tratándose de la regla sobre voto múltiple, su legalidad resultaba ciertamente discutible a la luz de las reglas tradicionales de una sociedad anónima ${ }^{43}$. Bajo este enfoque, la efectividad de las reglas opt-in debiera considerar su capacidad para entregar certeza y fomentar nuevas formas de organización en las empresas. Este tipo de análisis, sin embargo, requiere un tiempo de observación mucho mayor al nuestro, por lo que resulta difícil extraer mayores enseñanzas de la frecuencia relativamente baja con que se utilizan estas cláusulas.

\section{Los problemas de una administración convencional}

La libertad para configurar los mecanismos de gobierno corporativo constituye una de las características principales de una sociedad por acciones. Según se expuso en la sección anterior, cerca del $85 \%$ de los estatutos reemplaza la figura del directorio por una administración convencional. El problema es que los referidos estatutos carecen de una reglamentación completa para esta figura, limitándose a seguir el formato de las cláusulas de una SRL y enumerar los poderes de representación que se entregan a los administradores. Esto genera cierta contradicción entre las reglas que debieran aplicarse supletoriamente y las preferencias de quienes utilizan este tipo societario. Por una parte, la legislación sigue una orientación capitalista, donde la administración se entrega a un directorio que toma decisiones colectivamente y siguiendo un principio de mayoría. Por otra parte, la práctica mercantil privilegia un enfoque personalista, con un gobierno corporativo construido sobre la base de la delegación.

Tomemos el siguiente ejemplo. Imaginemos que una sociedad por acciones quiere celebrar un contrato con un tercero. A su vez, los estatutos delegan la administración en tres personas, pero sin detallar una regla que organice su proceso de toma de decisiones. En estas condiciones, sería necesario echar mano a las reglas supletorias que establezca la ley para determinar cuántos delegados serían necesarios a efectos de aprobar el contrato. En principio, existen dos soluciones posibles: podríamos considerar que cada delegado tiene poderes para actuar individualmente, o bien aplicar una regla de mayoría y exigir que al menos dos de los delegados aprueben el contrato. La administración convencional es una institución propia de las sociedades de personas, por lo que una interpretación funcional exigiría aproximarse a los estatutos de la sociedad por acciones de nuestro ejemplo desde esa orientación ${ }^{44}$. A su vez, cuando existen dos o más socios con facultades de administración se entiende que

43 PugA, J., La sociedad anónima y otras sociedades por acciones en el derecho chileno y comparado,

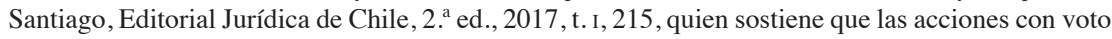
múltiple están prohibidas en la sociedad anónima.

44 Esta es la aproximación del Reino Unido respecto de la LLP. Las reglas sobre representación siguen las reglas de las partnership, aunque en materia de transferencia de los derechos sociales y otros aspectos de gobierno corporativo se remitan a las reglas de la corporation. Morse, G., "Partnerships 
pueden actuar individual y separadamente. Ahora bien: es importante tener en cuenta que estas reglas suponen que el delgado tenga también la calidad de socio. De hecho, suele señalarse que las facultades del delegado se interpretan con mayor extensión que las de un administrador externo o mandatario, en atención a la confianza que depositan los socios entre sí en una sociedad personalista ${ }^{45}$. Teniendo en cuenta que una sociedad por acciones se caracteriza por facilitar la libre transferencia de las acciones, resulta extraño apoyar nuestra supuesta interpretación funcional en un conjunto de reglas cuyo presupuesto es la permanencia del socio administrador.

Por otra parte, si los estatutos fueran interpretados teniendo en cuenta la remisión expresa a Ley de Sociedades Anónimas que realiza el artículo 424 del Código de Comercio, habría que asimilar a estos tres delegados a un directorio y aplicar la regla de mayoría ${ }^{46}$. Con todo, esta otra solución tampoco está exenta de problemas. El directorio solamente actúa en sala debidamente constituida y siguiendo un conjunto de formalidades para adoptar acuerdos. Al igual que en el caso anterior, resulta extraño exigir estas formalidades cuando los propios estatutos buscaban reemplazar el directorio con una estructura de gobierno corporativo más sencilla y menos burocrática. En definitiva, ninguna de nuestras alternativas de interpretación pareciera satisfacer la naturaleza híbrida de la sociedad por acciones. Mientras la confianza que supone la representación individual resulta difícil de justificar en un escenario de libre transferencia de derechos sociales, la regla de mayoría viene asociada a una burocracia que tampoco parece razonable a la luz de la mayor simpleza y flexibilidad perseguida con este nuevo tipo societario.

Algo similar ocurre cuando analizamos las relaciones de la sociedad con terceros. Siguiendo con nuestro ejemplo anterior, imaginemos ahora que los poderes de representación otorgados a los administradores delegados eran insuficientes para celebrar un contrato con un tercero y se vuelve necesario ratificar todo lo obrado. En particular, supongamos que los poderes delegados se refieren únicamente a bienes muebles, pero el contrato con un tercero consiste en la enajenación de un bien raíz. ¿A quién corresponde por defecto las facultades de representación en una sociedad por acciones cuya forma de administración es convencional? En principio, la regla supletoria prevista para una sociedad anónima supone la existencia de un directorio y radica en ese organismo todos los poderes de representación. Sin embargo, en nuestro ejemplo esa fue precisamente la forma de administración excluida por los accionistas. La lógica de una delegación supone que estas facultades estarían radicadas en los accionistas, pero esto solamente resuelve una parte del problema.

for the 21st Century - Limited Liability Partnerships and Partnership Law Reform in the United Kingdom”, Singapore Journal of Legal Studies, 2002, 465 y 470.

45 Pardow, D., "Potestades de administración y deberes fiduciarios", en Estudios de Derecho Civil II, Santiago, Lexis Nexis, 2006, 89-112.

46 En la sociedad colectiva comercial, la regla de mayoría también opera si existe oposición tanto en el caso de tres o más administradores conjuntos (artículo 399 Código de Comercio) como de administradores separados (artículo 390 Código de Comercio). 
De acuerdo con el artículo 427 del Código de Comercio, las reformas a los estatutos de una sociedad por acciones pueden aprobarse en una junta de accionistas, o bien mediante una escritura pública suscrita por todos los accionistas. En el primer caso se aplica una regla de mayoría, mientras en el segundo caso se exige unanimidad. Como las reglas sobre administración convencional forman parte de los estatutos, es claro que cualquier reforma hacia el futuro, incluyendo nuestro ejemplo sobre la enajenación de un bien raíz, podría materializarse de cualquiera de estas dos maneras. Ahora bien: resulta mucho menos claro si estas disposiciones pueden aplicarse a un escenario de ratificación. En concreto, ¿sería admisible que nuestro contrato fuera ratificado por la mayoría de los accionistas o sería necesaria la unanimidad? Nuevamente, este problema muestra las dificultades de adaptar estas reglas a la práctica mercantil en materia de sociedades por acciones. Mientras las sociedades de personas exigen unanimidad para las decisiones importantes, las sociedades de capital aplican una regla de mayoría ${ }^{47}$.

Con el objetivo de evitar estos problemas, un número creciente de legislaciones han establecido un conjunto de reglas obligatorias identificando el órgano representativo por defecto y protegiendo de este modo los intereses de terceros. Así, por ejemplo, en Francia el presidente de una sas tiene facultades legales de representación cuya extensión no pueden ser alteradas en los estatutos sociales, sin perjuicio de la libertad de los asociados para nombrar otros representantes ${ }^{48}$. De manera similar, tanto la ley modelo recomendada por la oEA como la Guía Legislativa sobre Entidades de Responsabilidad Limitada de Uncitral recomiendan el establecimiento de reglas imperativas sobre representación de la sociedad ${ }^{49}$. En definitiva, esta extendida práctica mercantil consistente en reemplazar el directorio por un esquema de administración convencional plantea desafíos importantes en materia de gobierno corporativo. Las reglas que deben gobernar los distintos procesos de toma de decisiones, así como la ausencia de un órgano de representación imperativo, introducen incertidumbres y hacen más compleja una figura contractual que estaba llamada a simplificar el funcionamiento de las empresas.

\section{Conclusiones}

A diferencia de otros países, la legislación chilena establece un régimen de sociedades por acciones con una marcada orientación capitalista, esto es, utiliza como regla supletoria los mecanismos de transferencia de derechos sociales y la estructura de

47 La unanimidad, con carácter general, se exige en la sociedad colectiva para "toda modificación substancial del contrato, salvo en cuanto el mismo contrato estatuya otra cosa" (artículo 2054.III c. c.).

48 Azarian, H., La société par actions simplifiée. Creation. Fonctionnement. Évolution, 2. a ed., Paris, Litec, 2007, 155.

49 Artículo 26 Ley Modelo sobre Sociedad por Acciones Simplificada oEA como la recomendación 14 Guía Legislativa sobre Entidades de Responsabilidad Limitada Uncitral. 
gobierno corporativo de las sociedades anónimas. Desde esta perspectiva, la práctica mercantil muestra dos tendencias interesantes. Una sociedad por acciones promedio tiene pocas modificaciones al estatuto propuesto por el legislador, destacando aspectos como la digitalización de las comunicaciones, la simplificación de los mecanismos de solución de controversias y otras maneras de reducir la burocracia asociada con el funcionamiento de una sociedad anónima. Resulta también llamativo que innovaciones introducidas por primera vez en el Código de Comercio, como las preferencias accionarias o los regímenes especiales de dividendos, hayan recibido poca aplicación práctica. Ambas circunstancias, sin embargo, son consistentes con una búsqueda de reglas sencillas que faciliten el emprendimiento.

En contraste, el reemplazo del directorio por una administración convencional plantea problemas dogmáticos, especialmente a la hora de aplicar las reglas sobre sociedades anónimas como régimen supletorio. Por un lado, organizar los procesos de toma de decisiones en función de la regla de mayoría exige una burocracia que pareciera ir contra de esta búsqueda de simpleza por parte de los emprendedores chilenos que eligen una sociedad por acciones. Por otra parte, criterios propios de las sociedades de personas, como sucede con la representación individual y las decisiones por unanimidad, resultan difíciles de justificar en un tipo societario que fomenta la libre transferencia de derechos sociales. Es de esperar que futuras reformas, ya sea en Chile o en otros países de Latinoamérica, enfrenten de mejor manera el régimen de sociedades por acciones. Esto supone, al menos, flexibilizar la aplicación supletoria de las reglas sobre sociedades anónimas y considerar un órgano de representación imperativo que proteja los intereses de terceros.

\section{Referencias}

Armour, J., Hansmann, H., Kraakman, R. y Pargendler, M., "What is Corporate Law?", en Krankman, R. et al., The Anatomy of Corporate Law. A Comparative and Functional Approach, 3. ' ed., Oxford, Oxford University Press, 2017, 1-28.

Ayres, I. y Gertner, R., "Filling gaps in incomplete contracts: An economic theory of default rules", The Yale Law Journal, vol. 99, 1989, 87-130.

AzARIAn, H., La société par actions simplifiée. Creation. Fonctionnement. Évolution.

BAIRD, D. y JACKson, T., "Fraudulent Conveyance Law and Its Proper Domain", en Vanderbilt Law Review, vol. 38, Issue 4, 1985, 829-885.

Caballero, G., "Comentario de jurisprudencia. Prescripción adquisitiva y cesión del derecho de participación en una sociedad de responsabilidad limitada", en Revista Chilena de Derecho Privado, n. . 20, 2013, 263-270. 
CARney, W., "Limited Liability Companies: Origins and Antecedents", University of Colorado Law Review, vol. 66, 1995, 855-880.

Comisión de Naciones Unidas para el desarrollo del Derecho Mercantil InternaCIONAL, Proyecto de guía legislativa sobre una entidad de responsabilidad limitada (A/CN.9/WG.I/WP.114), disponible en [https://undocs.org/es/A/CN.9/WG.I/WP.114] [consultado el 4 de mayo de 2019].

Cuneo, A., "El directorio como una forma de administración y representación de la sociedad colectiva”, Revista Chilena de Derecho, vol. 13, 1986, 453-462.

Easterbrook, F. y Fischel, D., The Economic Structure of Corporate Law, Cambridge, London, Harvard University Press, 1991.

Enriquez, L., Hertog, G., Kraakman, R. y Rock, E., "Corporate Law and Securities Markets", en The Anatomy of Corporate Law. A Comparative and Functional Approach, 3. ${ }^{a}$ ed., Oxford, Oxford University Press, 2017, 243-266.

Epstein, R., Simple Rules for A Complex World, Cambridge-London, Harvard University Press, 2009.

Goetz, Ch. y Scott, R., "The Limits of Expanded Choice: An Analysis of the Interactions Between Express and Implied Contract Terms", California Law Review, vol. 73, n. $^{\text {o } 2, ~ 1985, ~ 261-322 . ~}$

Goetz, Ch. y Scott, R., “The Mitigation Principle: Toward a General Theory of Contractual Obligation”, Virginia Law Review, vol. 69, Issue 6, 1983, 967-1024.

Geu, T., "Understanding the Limited Liability Company: A Basic Comparative Primer (Part One)", South Dakota Law Review, 37, 1992, 44-96.

JARA, A., “Sociedad por acciones. Ley 20.190”, Revista Chilena de Derecho, vol. 34, n. ${ }^{\circ} 2,251-288$.

MAQueRA, C., "La sociedad por acciones cerrada simplificada: nuevo régimen societario alternativo y su estudio comparativo con las sociedades por acciones simplificadas de Colombia, México y Argentina”, 14, disponible en [https://docplayer. es/109283224-La-sociedad-por-acciones-cerrada-simplificada.html] [consultado el 3 de mayo de 2019].

Mensaje Presidencial, Historia de la Ley 20.190, disponible en [www.bcn.cl/historiadelaley/nc/historia-de-la-ley/5361/]. 
Morse, G., "Partnerships for the 21st Century - Limited Liability Partnerships and Partnership Law Reform in the United Kingdom", Singapore Journal of Legal Studies, 2002, 455-488.

National Conference of Commissioners on Uniform State Laws, 2014, Uniform Limited Liability Company Act (2006, Last Amended 2013) with prefatory note and comments, disponible en [www.uniformlaws.org/viewdocument/final-act-withcomments-109? CommunityKey=bbea059c-6853-4f45-b69b-7ca2e49cf740 $\&$ tab=librarydocuments] [consultado el 5 de mayo de 2019].

OrganiZACión de los Estados AmERICANos, "Recomendaciones sobre la propuesta de proyecto de Ley Modelo sobre Sociedad por Acciones Simplificada", aprobado el 9 de marzo de 2012, disponible en [www.oas.org/es/sla/ddi/docs/Ley_Modelo_sobre_la_Sociedad_Acciones_Simplificada.pdf].

PARdow, D., "Potestades de administración y deberes fiduciarios", en Estudios de Derecho Civil II, Santiago, Lexis Nexis, 2006, 89-112.

Posner, R., Economic analysis of law, Little, Brown and Company, 3. a ed., 1986.

Pound, R., "Law in books and law in action", American Law Review, n. "44, 1910, 12-36.

Prado, A., Aspectos comerciales de las sociedades por acciones, Santiago, Cámara de Comercio de Santiago, 2007.

PugA, J., La sociedad anónima y otras sociedades por acciones en el derecho chileno y comparado, Santiago, Editorial Jurídica de Chile, 2. ed., 2017.

REYES, F., sAS La sociedad por acciones simplificada, 3. a ed., Bogotá, Legis, 2015.

Ribstein, L., The Rise of the Uncorporation, New York, Oxford, Oxford University Press, 2010.

Rioseco EnRíquez, G., "La administración de las sociedades de personas", Revista de Derecho de la Universidad de Concepción, n. ${ }^{\circ}$ 187, 1990, 7-26.

RIPERT, G., Aspectos jurídicos del capitalismo moderno, Granada, Comares, 2001.

Sandoval, R., "Sociedad por acciones", en Revista de Derecho de la Universidad de Concepción, n. . 21-222, 2007, 7-24. 
Schwartz, A., "Proposals for Products Liability Reform: A Theoretical Synthesis", Yale Law Journal, vol. 97, n. 3 , 1988, 353-419.

Thaler, R. y Sunstein, C., Nudge. Improving decisions About Health, Wealth, and Happiness, New Haven-London, Yale University Press, 2008.

VERÓn, A., "La sociedad por acciones simplificada de la ley 27.349”, en La Ley, 25 de abril de 2017 (AR/DOC/1027/2017), disponible en [htpps://thomsomreuterslatam.com/2017/04/la-sociedad-por-acciones-simplificada-de-la-ley-27.349/] [consultado el 2 de mayo de 2019].

Whittaker, J. y Machell, J., The Law of Limited Liability Partnerships, 3. a ed., Bloomsbury Professional, 2009. 